\title{
Reaction times for a same-different discrimination of vowel-consonant syllables
}

\author{
CHARLOTTE REED \\ Bioacoustics Laboratory, Eye and Ear Hospital and School of Medicine, \\ University of Pittsburgh, Pittsburgh, Pennsylvania 15219
}

\begin{abstract}
Reaction times (RTs) were measured for decisions in a same-different discrimination of successive vowel-consonant nonsense syllables. Averaged data showed that "same" RTs were faster than "different" RTs and that the "different" RT decreased as the number of features (Wickelgren, 1966) by which a pair contrasted increased. For individual phonemic comparisons, two of the dependent variables, $P(S \mid d)$, or probability of responding "same" to a different trial and the mean correct "different" RT, were related in that the RT increased as P(S I d) increased. The size of the difference between "same" and "different" RTs for a given phonemic contrast was directly related to $P(S \mid d)$. The difficulty of a comparison, as described by $\mathrm{P}(\mathrm{S} \mid \mathrm{d})$ and by the difference between correct "same" and "different" RTs, was explained through a markedness classification of phonemes.
\end{abstract}

Bindra, Donderi, and Nishisato (1968) have proposed that the relative response latency of "same" and "different" decisions in a discrimination task is a function of the codability of the test signals. Two of the experiments they reported involved stimuli that were readily codable. Verbal labels could be assigned easily to these stimuli, which were colors in the visual modality and clicks vs. pure tones in the auditory modality. For these stimuli, "same" reaction times (RTs) were faster than or equal to "different" RTs. For tasks involving stimuli that were not as readily codable (discrimination of pure tones, for example) the "diflerent" RT was signiticantly faster than the "same" RT. Other investigators have reported sinilar results, both for codable (Bamber. 1969, 1972; Burrows, 1972; Kreuger, 1970; Nickerson, 1965; Tversky, 1969) and noncodable signals (Bindra, Williams, \& Wise, 1965; Kellogg, 1931: Nickerson, 1969. 1971, 1972: Nishisato \& Wise, 1967).

McInish and Tikofsky (1969) extended these results to auditorily presented speech. They measured RTs for a same-different discrinination of consonantvowel $(C V)$ stimuli, with the vowel $/ a /$. Three lists of $121 \mathrm{CVs}$ were constructed, with each list having a different intersignal interval of 3,6 , or $12 \mathrm{sec}$. Different pairs contrasted one or two features (Miller \& Nicely, 1955). Their 12 subjects were instructed to respond whether each syllable in the list was "same"

\footnotetext{
This research was supported by a grant from NINDS (NS 12501) and by an SRS training grant (44-P.15072). The author wishes to thank the members of the advisory committee for her doctoral dissertation from which this paper was derived: Robert Bilger. Audrey Holland. Norma Hopkinson, Walt Jesteadt, Charles Perfetti, and Marilyn Wang. In addition, the author wishes to express her appreciation to the following persons who read earlier versions of the paper: L. Braida, H. Cairns, R. Cole, N. Durlach, and C. Trahiotis.
}

or "different" from the preceding syllable, Thus, each sound in the list (except the first and last) was used in two separate judgments. Their results showed a correlation between error rate and latency for the one-feature discriminations, thereby indicating that latency can be used as an index of discriminability. They also found that "same" comparisons had the shortest mean RT (397 msec) and one-feature contrasts had the longest mean RT $(466 \mathrm{msec})$, while two-feature contrasts had a mean RT of $427 \mathrm{msec}$.

Cole and Scott (1972) presented pairs of phonemes simultaneously and dichotically for a same-different comparison. Of their 40 subjects, half served in a consonant experiment and half in a vowel experiment. They used eight stimuli in each experiment. Their results indicated that the mean $\mathrm{RT}$ s for consonants were significantly faster than for vowels. Within the consonantal stimuli, their results showed an orderly decrease in RT as the number of contrasting features (Halle. 1964) increased from one to six. The "same" RT was faster than the "different" RT for pairs of consonants contrasting one to four features.

- Weiner and Singh (1974) measured RT for samedifferent judgments of nine English fricatives presented in CV syllables. The RTs were analyzed using multidimensional scaling, for which a four-dimensional solution was obtained. These dimensions were interpreted as the phonetic features of voicing, sibilant, front/back, and palatal. The time required for a "different" decision decreased as the number of features by which a pair contrasted increased, both for a classification of phonemes with the features derived from the scaling procedure and for a classitication of phonemes using the features derived by Miller and Nicely (1955).

None of the previous researchers have presented data for individual phonemic comparisons. Instead. 
they reported their data in terms of the means for all "same" trials and all "different" trials contrasting an equal number of features. The present study of RTs for individual phonemic comparisons was undertaken to determine the differential speed of "same" and "different" RTs for specific phonemic contrasts.

\section{METHOD}

Subjects

Four normally hearing young adults served as listeners. They were tested simultaneously in six 2.5 -h sessions. They were paid $\$ 2 / \mathrm{h}$.

\section{Stimuli}

Because the large number of English consonants discourages a factorial study, selection of a subset of consonants was necessary. Selection of this subset was aided by the availability of confusion matrices for VCs for 22 subjects with both normal and impaired hearing, collected by Bilger. Wang, and Jesteadt (1972). Five phonemes were selected as standards based on a tabulation of the frequency with which the phonemes were misidentified by these listeners. Three of the standards $(/ \partial /, / \mathrm{d} Z /$, and $/ 3 /)$ were the phonemes most frequently missed by the largest number of listeners. The phoneme / $/$ was chosen as a standard on the basis of its high degree of recognition by all listeners, and $/ g$ / was chosen as a phoneme of intermediate ditficulty.

For each of these five standards. four comparison phonemes were selected on the bases of confusion with the standard (as observed from the confusion matrices) and allowance for a range of feature differences. The standards and the phonemes chosen for comparison with each standard are listed in Table 1, along with the number of contrasting features (Wickelgren, 1966) for each pair. For the nonbinary place feature, each degree of difference between phonemes on this feature has been counted as a unit difference. Wickelgren's features have been used here because they were derived from consonantal confusions made in a short-term-memory task, and the same-different task used here presumably involves some use of short-term memory.

VC syllables (vowel / a ), recorded by a male talker and stored on a Cognitronics Speechmaker (Wang \& Bilger. 1973), were converted to digital form using a 10 -bit analog-to-digital converter and a $10-\mathrm{kHz}$ sampling rate. This sampling rate requires the use of a $5-\mathrm{kHz}$ low-pass filter to eliminate distortion products that overlap the speech frequencies. The digital values of the syllables were stored on a PDP-15 computer and subsequently plotted on an X-Y plotter by reconverting the digital values to analog form. The duration of all syllables was determined by visual inspection of these plots. The range of durations for syllables was 335 to $440 \mathrm{msec}$. All syllables were trimmed from the beginning and/or the end of the syllable to produce a duration of $335 \mathrm{msec}$, ensuring a uniform, prescribed duration for the same-different task. All of the syllables except for $/ a t i, / a g /, / a t \int /, / a d z^{/}, / a m /$, and $/ a b /$ were trimmed to some degree from the syllable onset. Only two syllables, $/ \mathrm{am} /$ and $/ \mathrm{ag} /$, were not trimmed from the end. Two listeners compared the trimmed and untrimmed versions of each syllable and decided if there were any noticeable differences in quality or intelligibility between the two sounds. Each of the final. trimmed syllables was judged to be an acceptable representation of the phoneme in question.

Tape-recording of the syllables for test presentation was effected under control of a PDP-15 computer in conjunction with an Ampex PR-10 tape recorder. The digitized values of the VCs were reconverted to analog form and passed through a $5 \cdot \mathrm{kHz}$ low-pass filter onto the tape recorder at a speed of 7.5 ips. The intersignal interval was $750 \mathrm{msec}$. The time between pairs of syllables was 6 sec. At playback the output of the tape recorder was passed through an attenuator into a four-way splitter which passed the signal into calibrated earphones (TDH-49) in each of four sound-treated rooms (IAC 401A). Syllables were presented at a level of $60 \mathrm{~dB} \mathrm{SPL}$ re a $1-\mathrm{kHz}$ calibration tone.

Twenty-five randomized lists, each consisting of 80 phoneme pairs. were recorded. Each list contained an equal number of "same" and "different" trials. Each of the four "different" comparisons with each standard was presented twice in a list $(40$ "different" comparisons per list), with the standard presented once as the first member of a pair and once as the second member. Each of the 5 stand ard phonemes $(/ \partial /, / \mathrm{d} 3 /, / 3 / . / \mathrm{g} /, / \mathrm{t} /)$ and each of the 10 comparison phonemes $\left(/ \mathrm{k} / . / \mathrm{d} /, / \mathrm{f} /, / \mathrm{s} /, / \mathrm{v} /, / \mathrm{z} /, / \int / \mathrm{c}\right.$

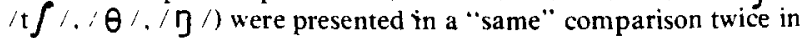
a list (resulting in 30 "same" comparisons). The 10 remaining "same" comparisons needed to balance the list were drawn from the phonemes $/ \mathrm{m} /, / \mathrm{n} /, / \mathrm{p} /$, and $/ \mathrm{b} /$, which were neither standards nor comparisons.

\section{Procedure}

The same-different procedure was run under computer control, Each trial was begun with a 500 -msec warning light, followed by the occurrence of the first syllable of a pair, which was marked by an observe light. A $750-\mathrm{msec}$ silent interval separated the first syllable from the second. and the presentation of the second syllable coincided with a light labeled "answer." This answer light remained on, for up to $4 \mathrm{sec}$ until the subject responded by pressing one of two buttons labeled SAME and DIFF. Correct-answer feedback was provided. The RT was measured with 1 -msec resolution by timing out the interval from the onset of the syllable to the depression of a button.

Six practice runs were conducted on the first day, three with each lett-right positioning of the response buttons. On the 5 subsequent days. subjects listened to 1080 -item lists per session. Each of the 25 lists was presented twice, resulting in 100 observations per comparison per subject. The button order of SAME-DIFF for the tirst half of the experiment was reversed for the second half. Subjects were instructed to answer as quickly and as accurately as possible and to respond using the index finger of the right hand. Subjects listened monaurally through the right ear.

\section{RESULTS}

Before analyzing individual phonemic comparisons. the data were examined in a manner comparable to the analyses reported by Cole and Scott (1972), McInish and Tikofsky (1969), and Weiner and Singh (1974) to determine the extent to which the present data

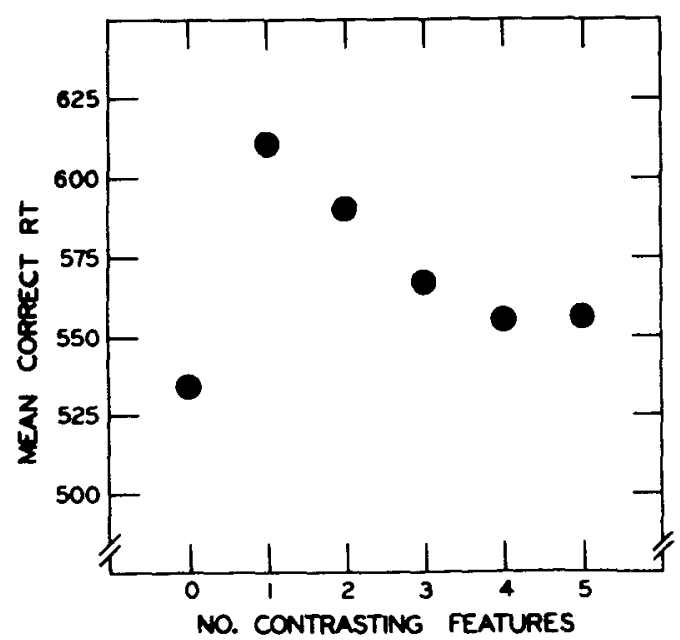

Figure 1. The mean correct RT across the four subjects plotted as a function of the number of contrasting features (Wickelgren, 1966). The "same" RT (0 contrasting features) is based on correct responses for 6,000 trials. The data points for $1,2,3,4$, and 5 contrasting features are based on correct responses for 4,400 , $1,200,1,200,400$, and 800 trials, respectively. 
replicate their results. The results of this analysis are presented in Figure 1, where the mean correct RT is plotted as a function of the number of contrasting features. The results are similar to those reported by the earlier experimenters in that the mean correct "different" RT decreased as the number of contrasting features increased. The mean correct "same" RT $(0$ contrasting features) was shorter than any "different" RT.

For signal detection and RT analyses of individual phonemic comparisons, the trials of interest were those for a given "different" comparison along with the "same" trials for each of the two phonemes that made up the "different" comparion. A fourfold stimulus-response matrix with dimensions of "same" and "different" was constructed for each comparison, with a total $\mathrm{N}$ of 300 trials per subject. Of these 300 trials, 100 were the "different" trials for a given comparison ( 50 in each order). The remaining 200 trials resulted from grouping the 100 "same" trials for each phoneme of the pair. For the comparison of $/ \mathrm{t}-\mathrm{d} /$, for example, the input "different" trials were the 50 presentations each of $/ \mathrm{t}-\mathrm{d} /$ and $/ \mathrm{d}-\mathrm{t} /$. The input "same" trials to the matrix were the 100 presentations each of $/ \mathrm{t}-\mathrm{t} / \mathrm{and} / \mathrm{d}-\mathrm{d} /$. Although the ratio of "same" to "different" trials is $2: 1$ in these matrices, the ratio of "same" to "different" trials in the experiment was 1:1. The cell entries in these matrices were either the number of each type of response for the signal detection analysis or the mean RT for each type of response.

"Same" trials with the two phonemes of a pair were grouped since the value of $P(S \mid s),{ }^{1}$ or probability of a "same" response to a same pair, did not vary greatly from phoneme to phoneme. Both the sensitivity index, $d^{\prime}$, and the criterion measure, $\beta$, were determined primarily by the observed quantity $P(S \mid d)$, or probability of a "same" response to a different pair. This finding can be explained by the fact that both $\mathrm{d}^{\prime}$ and $\beta$ are based on the relation between $P(S \mid s)$ and $P(S \mid d)$. The quantity $P(S \mid s)$ was a relatively stable value around 0.96 for all comparisons, while the quantity $P(S \mid d)$ varied from comparison to comparison. Thus, the subjects were employing only one of the two degrees of freedom available in each matrix. For this reason, performance data will be presented in terms of $P(S \mid d)$.

The discriminability of a phoneme pair may be assessed through two of the variables studied in this experiment, a performance measure $[P(S \mid d)$ in this case] and the time required to make a correct decision of "different." The value of $P(S \mid d)$ for each of the "different" comparisons is provided in the fourth column of Table 1. The relation between $P(S \mid d)$ and the mean correct "different" RT is given, in Figure 2, for phonemic pairs that covered the range of $P(S \mid d)$ observed in the experiment. The size of the mean correct "different" RT increased as $P(S \mid d)$ increased.

An independent variable, that of the number of
Table 1

A List of the 20 Phonemic Comparisons (Four Comparisons With Each of Five Standards) and the Feature Differences (Wickelgren, 1966) Between Each Pair

\begin{tabular}{|c|c|c|c|c|}
\hline \multirow{2}{*}{$\begin{array}{l}\text { Phonemic } \\
\text { Pair }\end{array}$} & \multicolumn{2}{|c|}{$\begin{array}{c}\text { Feature Differences } \\
\text { (Wickelgren, 1966) }\end{array}$} & \multirow[b]{2}{*}{$\mathrm{P}(\mathrm{S} \mid \mathrm{d})$} & \multirow{2}{*}{$\begin{array}{l}\text { Key to } \\
\text { Figures } \\
2 \text { and } 3\end{array}$} \\
\hline & Number & Features & & \\
\hline$|3-\mathrm{v}|$ & 1 & P & .19 & 0 \\
\hline$/ 3-d /$ & 1 & 0 & .17 & $\odot$ \\
\hline$|\partial-\theta|$ & 1 & V & .10 & 0 \\
\hline$|\bar{\partial}-\mathrm{g}|$ & 4 & $\mathrm{O}, \mathrm{P}(3)$ & .04 & $\bullet$ \\
\hline $\mid d \overline{5}-t\} \mid$ & 1 & $\mathrm{~V}$ & .09 & $\square$ \\
\hline $\mid d \overline{3}-\mathrm{g} /$ & 1 & $P$ & .02 & $\varpi$ \\
\hline$/ \mathrm{d} \overline{3}-\mathrm{d} /$ & 2 & $P(2)$ & .02 & - \\
\hline$|d z-f|$ & 5 & $\mathrm{~V}, \mathrm{O}, \mathrm{P}(3)$ & .03 & 0 \\
\hline$|3-z|$ & 1 & $\mathbf{P}$ & .20 & 0 \\
\hline$|\vec{z}-1|$ & 1 & V & .04 & 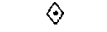 \\
\hline$|\overline{3}-\mathrm{g}|$ & 2 & $\mathrm{O}, \mathrm{P}$ & .04 & $\bullet$ \\
\hline$|\overline{3}-\mathrm{d} Z|$ & 1 & $\mathrm{O}$ & .04 & $\bullet$ \\
\hline$/ \mathrm{g}-\mathrm{d} /$ & 3 & $\mathbf{P}(3)$ & .05 & $\Delta$ \\
\hline /g-k/ & 1 & $\mathrm{~V}$ & .06 & $\theta$ \\
\hline$|g-\eta|$ & 1 & $\mathbf{N}$ & .04 & $\Delta$ \\
\hline$|g \theta|$ & 5 & $\mathrm{~V}, \mathrm{O}, \mathrm{P}(3)$ & .06 & $\Delta$ \\
\hline$|t-s|$ & 2 & $0, P$ & .09 & $\nabla$ \\
\hline$|t-d|$ & 1 & $\mathrm{~V}$ & .05 & $\nabla$ \\
\hline$|t-v|$ & 3 & $\mathrm{~V}, \mathrm{O}, \mathrm{P}$ & .02 & $\nabla$ \\
\hline$|t-z|$ & 3 & $\mathrm{~V}, \mathrm{O}, \mathrm{P}$ & .02 & $\nabla$ \\
\hline
\end{tabular}

Note-The four features in this system are voicing (V), open ness $(O)$, nasality $(N)$, and place $(P)$. Each degree of difference along the place feature has been counted as a unit difference. Also provided are the $P(S \mid d)$, or probability of responding "same" to each "different" pair, and the key to Figures 2 and 3.

features (Wickelgren, 1966) by which a pair of phonemes contrasted, was also related to the observed variables. The largest values of $P(S \mid d)$ were observed with one-and two-feature contrasts. When the number of contrasting features was three or more, $P(S \mid d)$ was below 0.05 . A wide range of $P(S \mid d)$ values was observed, however, with the one-feature contrasts. While certain minimal pairs yielded high $P(S \mid d)$ rates, others yielded rates as low as those obtained for

Table 2

Mean Correct "Same" RTs and Mean Values of P(S|s), or Probability of a Correct "Same" Response, for the 15 Phonemes that Were Either Standards or Comparisons

\begin{tabular}{|c|c|c|c|}
\hline Phoneme & $\begin{array}{l}\text { Mean Correct } \\
\text { "Same". RT } \\
\text { in Msec }\end{array}$ & $P(S \mid s)$ & $\begin{array}{c}\text { Marked- } \\
\text { ness } \\
\text { Value }\end{array}$ \\
\hline$/ \widetilde{\partial}$ & 562 & .96 & 4 \\
\hline$|3|$ & 577 & .96 & 4 \\
\hline$|\mathrm{a} 3|$ & 575 & .96 & 3 \\
\hline$|s|$ & 537 & .95 & 3 \\
\hline$|\theta|$ & 542 & .92 & 3 \\
\hline$|v|$ & 524 & .96 & 3 \\
\hline$|z|$ & 542 & .97 & 2 \\
\hline$|\mathrm{f}|$ & 530 & .95 & 2 \\
\hline$|\mathrm{t} s|$ & 488 & .97 & 2 \\
\hline$|g|$ & 590 & .94 & 2 \\
\hline$|\mathrm{n}|$ & 452 & .98 & 2 \\
\hline$/ \mathrm{s}$ & 487 & .98 & 1 \\
\hline$/ d /$ & 560 & .93 & 1 \\
\hline$/ \mathrm{k}$ & 493 & .97 & 1 \\
\hline$|t|$ & 550 & .96 & 0 \\
\hline
\end{tabular}

Note-Results are averaged across the four subjects and are based on a total of 400 observations per phoneme. The final column of the table is the markedness value of each phoneme. 


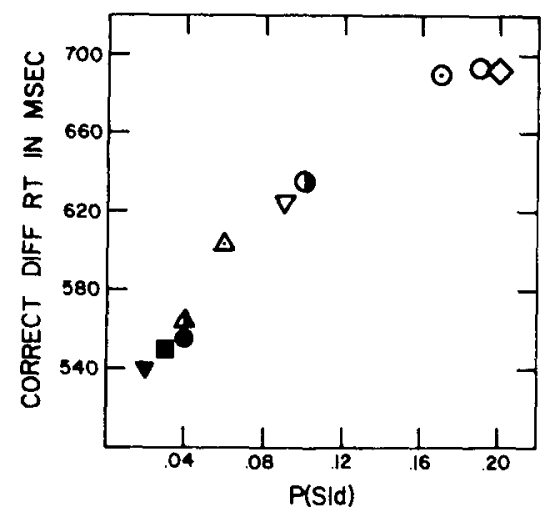

Figure 2. The mean correct "different" RT for 10 phonemic comparisons plotted as a function of $P(S \mid d)$. Data points are means across subjects, and each point is based on $\mathbf{4 0 0}$ observations. The key to this figure is provided in Table 1.

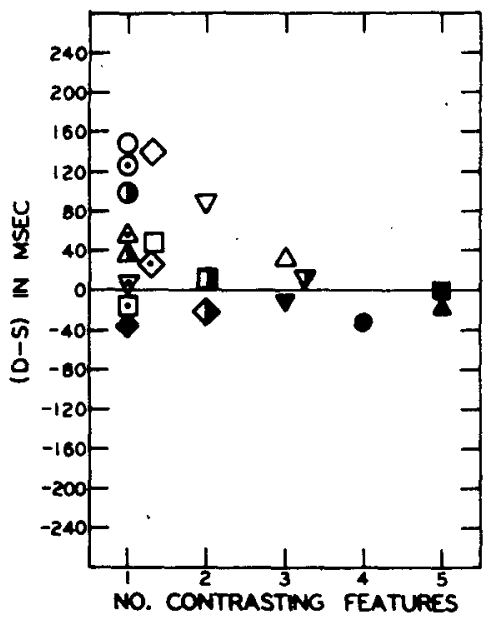

Figure 3. The difference between mean correct "different" and "same" RTs, (D - S), for individual phonemic comparisons plotted as a function of the number of contrasting features (Wickelgren, 1966). Data points are means across subjects and are based on 1,200 observations per point. The key to this figure is provided in Table 1.

contrasts of more than two features. The one-feature contrasts with the highest values of $P(S \mid d)$ were $/ z^{-z /}(.20), / \succsim-\mathrm{v} /(.19), / \succsim-\mathrm{d} /(.17), / \succsim \theta /$ (.10), and $/ \mathrm{d} 3-\mathrm{t} \int /(.09)$. A P(S $\left.\mid \mathrm{d}\right)$ of .09 was also obtained for the two-feature contrast of $/ \mathrm{t}-\mathrm{s} /$.

Values of P(S | s) and correct "same" RTs, averaged across the four subjects, are given in Table 2 . It can be seen that $P(S \mid s)$ did not vary greatly from phoneme to phoneme. The phonemes are arranged by their markedness values, a topic that will be raised in the discussion of the results.

The difference between the mean correct "different" RT and the mean correct "same" RT, (D - S), was computed for each of the 20 comparisons from the matrices previously described. The size of $(D-S)$ was examined, in Figure 3 , as a function of the number of features (Wickelgren, 1966) by which the "different" pair contrasted. The size of (D-S) increased as the number of features. by which the pair contrasted decreased. The largest values of $(D-S)$ were observed for certain of the one-feature contrasts. These comparisons also had the highest values of $P(S \mid d)$. A wide range of $(D-S)$ values was observed anong the one-feature contrasts.

Mean RTs for incorrect decisions, averaged across the four subjects, are given in Table 3. The "different" stimuli have been grouped according to the number of features by which the pair contrasted. The mean correct RTs, shown in Figure 1, have been repeated here so that $\mathrm{RTs}$ for correct and incorrect decisions can be compared. An incorrect response of "same" to a different stimulus, (S|d), was the fastest of any of the RTs in all cases except for that of three contrasting features. The next fastest RT was for a correct "same" decision, (S $\mid$ s). The RT for an incorrect response to a "same" stimulus, (D | s), was generally $40 \mathrm{msec}$ longer than for the correct "same" response. The longest RTs generally were for correct "different" decisions, (D | d).

\section{DISCUSSION}

Mean RT results, presented in Figure 1, indicate that "same" RTs were faster than "different" RTs and that the "different" RTs were a function of the number of contrasting features (Wickelgren, 1966). "Same" and "different" RTs were then examined for individual phonemic comparisons in terms of a difference measure, (D-S), between the two RTs. The results (Figure 3) showed a wide range of variability in this measure for comparisons contrasting an equal number of features, particularly for the one-feature contrasts. Thus, the average data are not generalizable to results obtained for individual phonemic comparisons.

Comparisons for which large values of $(D-S)$ were obtained also had the largest values of $P(S \mid d)$. These comparisons were $/ \partial-v /, / \partial-d /, / \partial-\theta /, / \zeta-z /$. $/ \mathrm{d} 3^{-\mathrm{t}} \int /$, and $/ \mathrm{t}-\mathrm{s} /$, all one-feature contrasts except for the two-feature contrast of $/ \mathrm{t}-\mathrm{s} /$. . Three of the four distinctive features in the Wickelgren (1966) system (voicing. openness, and place) provided minimal contrasts for these comparisons. The fourth feature, nasality. was contrasted minimally in only one comparison, $/ g-\eta /$, for which $P(S \mid d)$ was low. Thus, the difficulty of a comparison, as described by $P(S \mid d)$ and $(D-S)$, does not appear to be related to

Table 3

RTs in Milliseconds for Correct and Incorrect Responses to "Same" Stimuli and to "Different" Stimuli Grouped According to the Number of Features by Which a Pair Contrasts

\begin{tabular}{|c|c|c|c|c|c|c|}
\hline & \multirow[t]{2}{*}{$\begin{array}{l}\text { "Same" } \\
\text { Stimuli }\end{array}$} & & \multicolumn{4}{|c|}{$\begin{array}{l}\text { "Different" Stimuli } \\
\text { Number of Contrasting Features }\end{array}$} \\
\hline & & & 1 & 2 & 3 & $4 \& 5$ \\
\hline $\mathrm{S} \mid \mathbf{S}$ & 534 & DId & 611 & 591 & 567 & 556 \\
\hline $\mathrm{D} \mid \mathrm{s}$ & 572 & $S \mid d$ & 492 & 416 & 626 & 493 \\
\hline
\end{tabular}

Note-RTs are averaged across the four subjects. In the notation used to describe the stimulus-response condition, a capital letter denotes a response and a lowercase letter denotes the stimulus. 
minimal contrast on a particular feature.

Previous reports in the literature for data averaged across comparisons that contrast an equal number of features have led to the expectation that RTs and error rates should be a function of the number of contrasting features. The findings of the present study were contrary to this expectation in that the total range of experimental results was observed among the 11 comparisons that contrasted one feature. This result indicated that the factors determining $P(S \mid d)$ and (D-S) involved something other than feature differences between phonemes. Thus, a search was begun for some other phonological property of sounds that could account for the gradations in difficulty among comparisons contrasting one feature. The concept of markedness (Cairns, Cairns, \& Williams, 1974; Chomsky \& Halle, 1968) seemed to lend itself to an explanation of the variability of results obtained among the one-feature contrasts.

Although the concept of markedness is too complex to present fully in the present context, the basic percepts can be elucidated. Each of the features that makes up a phoneme is assigned a value of "marked" or "unmarked," determined by such things as "ease of articulation, perceptual saliency, and frequency of occurrence in languages of the world" (Cairns, et al., 1974, p. 161). The number of marked features for a given phoneme is an indication of its overall complexity, with a high markedness value corresponding to a high degree of complexity. The markedness values shown in Table 2 were taken from Cairns et al. (1974, Table 1, p. 162). The feature system to which markedness values were applied was that of Chomsky and Halle (1968). These markedness values range from 0 to 4 . Of the phonemes used as standards, / / / and / $/$ / have markedness values of $4 . / \mathrm{d} z / \mathrm{a}$ value of $3, / \mathrm{g} / \mathrm{a}$ value of 2 , and $/ t /$ a value of 0 .

Three of the comparisons with high $\mathrm{P}(\mathrm{S} \mid \mathrm{d})$ rates involved / $\partial /$ a highly complex phoneme according to a markedness classification. The other more complex phonemes. $/ 3 /$ and $/ \mathrm{d} / /$ were involved in one comparison each when high $\mathrm{P}(\mathrm{S} \mid \mathrm{d})$ rates were obtained. Thus, most of the comparisons which yielded high $P(S \mid d)$ rates involved phonemes that were complex according to a markedness classification.

Difficulty or degree of complexity appears to have been a major factor in determining the size of the difference between "different" and "same" RTs. The effect of difficulty on RTs in a same-different task has been investigated by Bindra, Donderi, and Nishisato (1968) for discriminations of lengths of lines. Discriminability was varied by changing the similarity of the lengths of lines to be compared. For the low and medium levels of difficulty, the "different" RT was faster than the "same" RT. For the high level of difficulty, however, this order was reversed, with a faster "same" than "different" RT. Overall latencies increased with the degree of similarity between lines, but the size of the "different" RT increased relative to that of the "same" RT for a high level of difficulty. A similar effect was observed in the present experiment in that the "different" RT and (D-S) increased as $P(S \mid d)$ increased.

Bamber (1969) has postulated a model of same-different decision making to explain his observation of faster observed than predicted "same" RTs. His model involves a rapid identity reporter operating simultaneously with a serial, dimensional processor. The rapid identity reporter processes stimuli as "gestalts" rather than on separate dimensions and can reach a decision of "same" faster than the serial processor. The decision-making process is terminated by the rapid identity processor only on the emission of a "same" response; otherwise, the serial process continues until either a "same" or a "different" decision is reached. Most "same" comparisons are assumed to be detected by the rapid identity reporter, thereby accounting for the observed faster "same" decision time. The RT for a decision mediated by the slower serial processor is an inverse function of the number of dimensions on which the two stimuli differ.

This model accounts for the data shown in Figure 1. The RTs for incorrect decisions, given in Table 3, may give additional insight into how the model can account for errors. Generally, an incorrect decision of "same," (S | d), was faster than a correct "same" decision, (S| s). In terms of Bamber's model, a fast incorrect "same" response is the result of an incorrect decision by the rapid identity reporter. An incorrect decision of "different," (D | s), generally took longer than any correct or incorrect "same" response, indicating that incorrect "different" decisions were mediated by the serial processor. Incorrect "different" decisions tended to be faster than correct "different" responses. This finding suggests that when the correct "same" response is not triggered by the rapid identity reporter, then, if the serial dimensional process is not carried out to its completion (resulting in a correct decision and a long "same" RT), a premature decision of "different" based on false information is made. Thus, both types of errors appeas to be the result of incomplete processing by either the rapid identity reporter or the serial processor.

Although Bamber's model accounts for the averaged data shown in Figure 1, it does not explain the large differences in RTs among the one-feature contrasts. This finding has been explained by a markedness classification of phoneme complexity. When a highly marked, that is, complex, phoneme is involved in a one-feature contrast, then both error rate and the time required for a "different" decision may increase. As the "difficulty" of a comparison increases, the size of the "different" RT with respect to the "same" RT increases. 


\section{REFERENCES}

BAMBER, D. Reaction times and error rates for "same""different" judgments of multidimensional stimuli. Perception \& Psychophysics, 1969, 6. 169-174.

BAMBER, D. Reaction times and error rates for judging nominal identity of letter strings. Perception \& Psychophysics, 1972, 12. 321-326.

Bilger, R. C., Wang, M. D.. \& Jesteadt, W. Consonant confusions in patients with hearing loss. Journal of the Acoustical Society of America, 1972, 52, 113 (A).

Bindra. D., Donderi, D. C., \& Nishisato, S. Decision latencies of "same" and "different" judgments. Perception \& Psychophysics, 1968, 3, 121-130.

Bindra, D., Williams, J, A., \& WiSE, J. S. Judgments of sameness and difference: Experiments on decision time. Science, 1965, 150, 625-627.

BurRows. D. Modality effects in retrieval of information from short term memory. Perception \& Psychophysics, 1972, 11, 365-372.

Cairns, H. S., Cairns, C. E., \& Williams, F. Some theoretical considerations of articulation substitution phenomena. Language and Speech, 1974, 17, 160-173.

Chomsky, N., \& Halle, M. The sound pattern of English. New York: Harper and Row, 1968.

Cole, R. A., \& Scotr, B. Distinctive feature control of decision time: Same-different judgments of simultaneously heard phonemes. Perception \& Psychophysics, 1972, 12, 91-94.

Green, D. M., \& Swets, J. A. Signal detection theory and Psychophysics. New York: Wiley, 1966.

Halle. M. On the bases of phonology. In J. A. Fodor and J. J. Katz (Eds.). The structure of language. Englewood Cliffs, N.J: Prentice-Hall, 1964.

Kellogg, $W$. N. The time of judgment in psychometric measures. A merican Joumal of Psychology, 1931, 43, 65-86.

KREUGER. L. E. Effect of bracketing lines on speed of "same". "different" judgments of two adjacent letters. Journal of Experimental Psychology, 1970, 84, 324-330.

McINish, J. R., \& Tikofsky, R. S. Distinctive features and response latencies: A pilot study. Perception \& Psychophysics. 1969, 6. 267-268.

Mille R, G. A., \& Nicely, P. An analysis of perceptual confusions among some English consonants. Journal of the Acoustical Society of America, 1955, 27, 338-352.

Nickerson, R. S. Response times for "same"-"different" judgments. Perceptual and Motor Skills, 1965, 20, 15-18.

Nickerson, R. S. 'Same'-'different' response times: A model and a preliminary test. Acta Psychologica, 1969, 30. 257-275.

Nickerson, R. S. Same-different response times: A further test of a 'counter and clock' model. Acta Psychologica, 1971, 35. 112-127.

Nickerson, R. S. Auditory codability and the short-term retention of visual information. Journal of Experimental Psychology, 1972, 95, 429-436.

Nishisato. S., \& Wise, J. S. Relative probability, interstimulus interval. and speed of the same-different judgment. Psychonomic Science. 1967, 7, 59-60.

TVErsky, B. Pictorial and verbal encoding in a short-term memory task. Perception \& Psychophysics, 1969, 6, 225-233.

W ANG, M. D., \& Bilger, R. C. Consonant confusions in noise: A study of perceptual features. Journal of the Acoustical Society of America, 1973, 54, 1248-1266.

WEINER. F. F., \& Singh. S. Multidimensional analysis of choice reaction time judgments on pairs of English fricatives. Journal of Experimental Psychology, 1974, 102, 615-620.

WickelgReN, W. A. Distinctive features and errors in short-term memory for English consonants. Journal of the Acoustical Society of America. 1966, 39, 388-398.

\section{NOTE}

1. The notational convention adopted by Green and Swets (1966) is used here: that is. lowercase letters represent a stimulus and uppercase letters, a response.

(Received for publication February 12, 1975; accepted April 14, 1975.) 